Gut, 1969, 10, 63-67

\title{
Water and sodium absorption by the intestine in cholera
}

\author{
A. H. G. LOVE \\ From the Department of Clinical Investigation, US Naval Medical Research Unit No. 2, Taipei, Taiwan, \\ and Department of Medicine, The Queen's University of Belfast
}

How the copious diarrhoea in acute cholera is produced is poorly understood. It may be due to overproduction of fluid normally entering the gastrointestinal tract, to failure of reabsorption of the normal volume of such fluid, or to a combination of both defects (Watten, Morgan, Songkhla, Vanikiati, and Phillips, 1959). The demonstration of an inhibitor of sodium transport, using shortcircuited frog skin, in cholera stool has focused attention recently on the major role of a defect in absorption rather than on overproduction (Huber and Phillips, 1960).

The present studies investigated the changes in water and sodium transport in the rabbit small intestine which had been shown (De and Chatterje, 1953) to accumulate luminal fluid when exposed to vibrio or their products. This animal model may more closely resemble the human intestinal disturbances in cholera than frog skin preparations.

\section{METHODS}

Rabbits of local breed, weighing 1.5 to $2 \mathrm{~kg}$, were anaesthetized by intravenous nembutal. Isolated loops of jejunum, 8 to $10 \mathrm{~cm}$ in length, were constructed, leaving their blood supply intact on the mesenteric pedicle. The ends of the loops were cannulated to allow fluids to be introduced and removed. The continuity of the remaining small intestine was reestablished. The loops were replaced in the abdominal cavity and the midline incision was closed around the cannulae. Two loops were prepared in each animal. Studies either began immediately in the case of experiments with the animals exposed to toxins or an inoculum of vibrio was made into one of the loops to be studied at intervals subsequently. A freshly prepared culture of vibrio was placed in one of the two loops. A similar volume of the same material heated to $80^{\circ} \mathrm{C}$ for 30 minutes was placed in the other loop. The cephalic and caudad loops were used alternately as control and experimental loops. In all cases the cholera vibrio was an Inaba strain (NIH type 35A3) harvested after two hours' incubation in alkaline peptone water at $37^{\circ} \mathrm{C}$. The inoculum consisted of $10^{7}$ to $10^{9}$ organisms suspended in
$1 \mathrm{ml}$ saline. In other studies the experimental loop was exposed to cholera toxin (Jenkin and Rowley, 1959) produced by ammonium sulphate precipitation of sonicated vibrios. Cholera filtrate (Huber and Phillips, 1960) was also studied after Seitz-filtering stools from two cholera patients; in both these cases $1 \mathrm{ml}$ of toxin or filtrate containing $1 \mathrm{mg}$ protein per millilitre was inoculated. Twenty-six studies were carried out with vibrio infection and 12 each for both toxin and filtrate.

To study water and sodium transport in the loops $5 \mathrm{ml}$ of an electrolyte solution containing sodium 140 , potassium 10, chloride 110 , and bicarbonate $40 \mathrm{~m}$-equiv/l. was placed in the intestinal lumen for 10-minute periods. The solutions were injected at body temperature which was maintained at $37^{\circ} \mathrm{C}$ throughout the studies. Net absorption was calculated from input-output balance, estimated by volumetric recovery and in some studies by changes in dilution of a nonabsorbable marker (PEG). Chemical determinations of sodium and potassium were made with a Coleman flame photometer, of chloride by a Cotlove titrator, and of bicarbonate as $\mathrm{CO}_{2}$ by the manometric method of van Slyke. Osmolalities were measured with a Fiske osmometer.

Unidirectional fluxes of sodium ion were determined simultaneously by using both isotopes of sodium. The extracellular fluid of each animal was labelled by injecting 2 microcuries of ${ }^{24} \mathrm{Na}$ intravenously. This was done at least two hours before absorption studies commenced to allow adequate mixing. The electrolyte solution instilled into the loops was labelled with ${ }^{22} \mathrm{Na}$ at a concentration of 2.5 microcuries per litre. Sodium 22 and 24 activities were determined by counting loop fluid samples immediately after the study and then recounting after a lapse of one week when the levels of sodium 24 had decayed to negligible values. Counting was carried out in a $2 \times 2$ sodium iodide well-type scintillation counter, $2 \mathrm{ml}$ samples being counted to a minimum of 10,000 counts. The unidirectional fluxes were calculated as follows:-

\footnotetext{
Lumen to plasma (L-P) $=$

$\left(\begin{array}{c}\text { (total Na m-equiv) } \\ \text { (injected) }\end{array}\right)\left(\begin{array}{c}\text { Counts } / \text { min injected }- \text { counts } / \text { min } \\ \text { recovered } \times 100\end{array}\right)$

Plasma to lumen $(\mathrm{P}-0)=$
}

Total counts recovered

Specific activity of ${ }^{24} \mathrm{Na}$ in plasma (CPM/m-equiv) 
These values are expressed as $\mu$-equiv (sodium ion)/g wet intestine weight/hour.

\section{RESULTS}

Figure 1 shows the net transport of water and electrolytes across the intestinal mucosa in control and vibrio-infected loops. In the normal loop net absorption was $2.32 \pm 0.40 \mathrm{ml} / \mathrm{g} / \mathrm{hr}$ whereas in the infected loop net accumulation $1.48 \pm 0.32 \mathrm{ml} / \mathrm{g} / \mathrm{hr}$ was observed. The values are the mean and standard deviation of 26 paired studies. Similar changes were seen in net sodium transport and if the composition of fluid either absorbed or accumulating is calculated it is approximately the same concentration of sodium ion as plasma, $140 \mathrm{~m}$-equiv/l. Chloride and bicarbonate, which were absorbed by the normal mucosa, accumulated in the infected loop. Little change was seen with potassium transport.



FIG. 1. Net transport of water and electrolytes in normal and infected intestinal loops. Vibro infection 12 hours.

Figure 2 records the changes of unidirectional sodium ion fluxes which accompanied the net alterations in sodium transport noted in Figure 1. There was a marked increase in plasma-to-lumen flux (control 810.6 $\pm 70 \cdot 5$, infected 1,240.1 $\pm 80 \cdot 9$ $\mu$-equiv $/ \mathrm{g} / \mathrm{hr}$ ). At the same time there was no change in the lumen-to-plasma flux from control values (control 1,110.2 $\pm 90 \cdot 5$ and infected 1,060.8 \pm $100 \cdot 5 \mu$-equiv/hr). This pattern of ion flux disturbance was seen in loops infected with live vibrio, or exposed to either Jenkin and Rowley toxin or to cholera filtrate. All the values are significantly different $(P<0.001)$ from the control in terms of the plasma-to-lumen flux. The plasma-to-lumen flux has been determined in 12 studies by subtracting the measured lumen-to-plasma flux from the net sodium absorption and in 14 by two simultaneous sodium labels which measured both lumen-to- plasma flux and plasma-to-lumen flux directly. In these latter studies there was close agreement between the net transport measured chemically and algebraic summation of the separate ionic fluxes.

In Fig. 3 the effect of time of exposure to the vibrio on sodium ion fluxes is shown. After four hours' infection absorption still occurred but was less than in the control; at eight hours net accumulation in the lumen of sodium began and this was accentuated after 12 hours. After 24 hours of infection the bowel behaved as an inert membrane with no net movement across the mucosa. Exposure to cholera toxin produced a more rapid effect



FIG. 2. Net water transport, net sodium, and unidirectional ion fluxes in control, vibrio-infected, J.R. toxin, and cholera filtrate exposed intestinal loops. Infection time 12 hours. Toxin exposure time four hours.



FIG. 3. The effect of length of exposure of the intestine to cholera vibrio on net water, net sodium absorption, and unidirectional sodium ion fluxes in intestinal loops. 


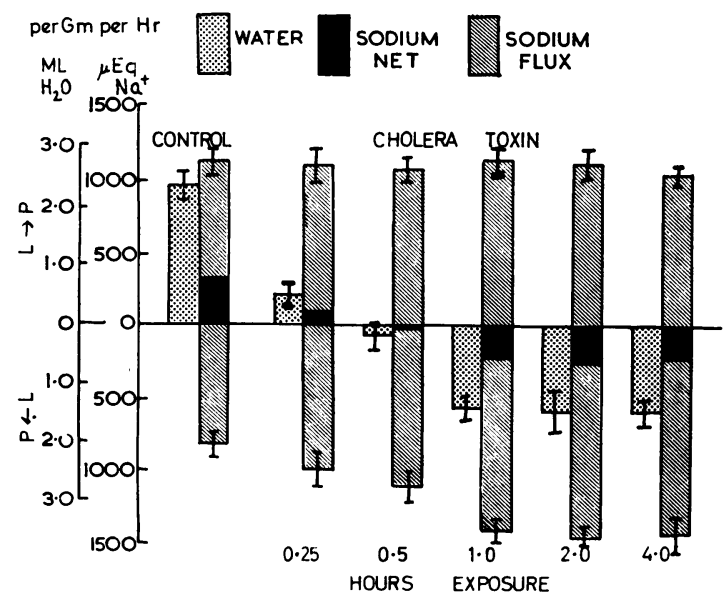

FIG. 4. Effect of exposure time of the intestinal loop to J.R. toxin on net water, net sodium absorption, and unidirectional sodium ion fluxes.

which reached a plateau of activity after one hour (Fig. 4).

The transport of water and sodium by mucosal cells of both the jejunum and ileum was disturbed by exposure to vibrio. The main difference is that the unidirectional fluxes of sodium ion were greater in the jejunum (Fig. 5). The changes in net transport of sodium in the infected loop were due to an increase in plasma-to-lumen flux in both areas of the small intestine. These findings are in agreement with those of Fordtran, Rector, Ewton, Soter, and Kinney (1965) who have demonstrated greater permeability of the jejunum than of the ileum in man.

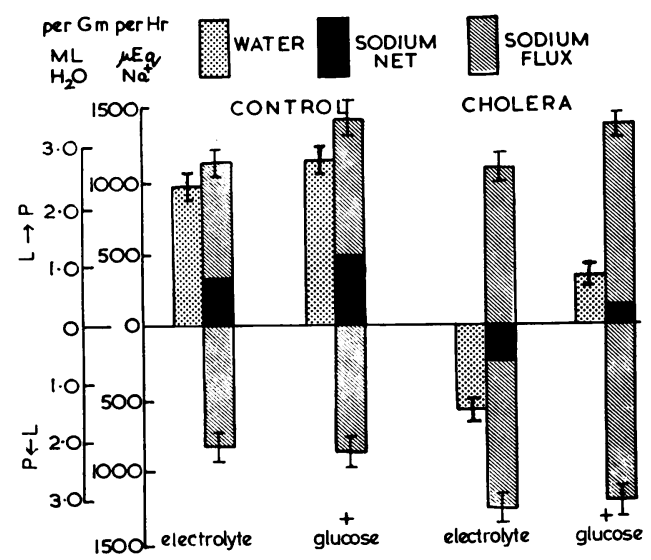

FIG. 6. Effect of glucose on electrolyte transport in normal and intestinal loops exposed to vibrio infection for 12 hours.

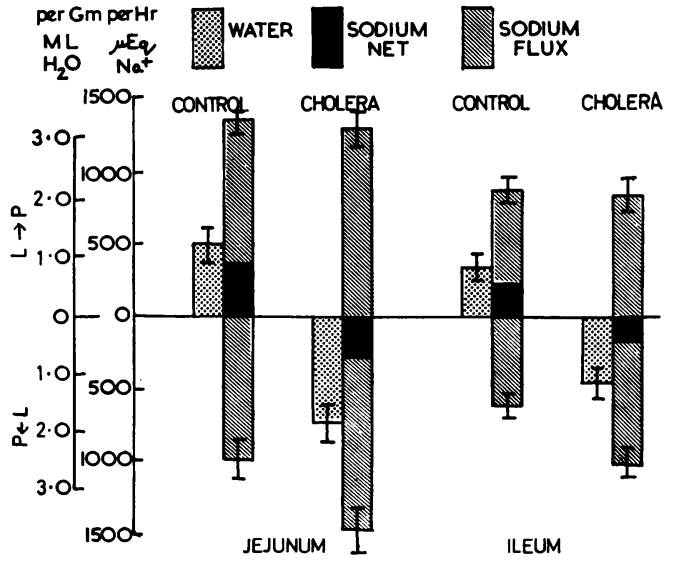

FIG. 5. Net water, net sodium transport, and unidirectional sodium fux in jejunal and ileal loops after 12 hours' exposure to cholera vibrio.

Figure 6 shows the effects of glucose absorption on water and sodium transport in the normal infected loops. Glucose was present in the luminal fluid at a concentration of $20 \mathrm{mMol}$. Simultaneous absorption of glucose enhanced the lumen-to-plasma flux of sodium ions by $29.4 \%$. This resulted in a $46.4 \%$ increase in net sodium absorption. Net water absorption is similarly increased by $17.5 \%$, the fluid transported remaining isotonic. There was no change in the plasma-to-lumen sodium flux. In the infected loop glucose absorption was not decreased, being $84 \cdot 4 \pm 10.8 \mu \mathrm{mol} / \mathrm{g} / \mathrm{hr}$ in the controls and $82 \cdot 3 \pm 12 \cdot 2 \mu \mathrm{mol} / \mathrm{g} / \mathrm{hr}$ in the infected loops. Glucose absorption increased the sodium flux from lumen to plasma to a similar degree to that in the control series. This enhancement of sodium ion flux resulted in a change from net accumulation in the lumen of $204.3 \pm 48.5 \mu$-equiv $/ \mathrm{g} / \mathrm{hr}$ to net absorption of $102.8 \pm 26.4 \mu$-equiv $/ \mathrm{g} / \mathrm{hr}$ in the infected loop. Water was absorbed in isotonic proportion, net absorption being produced by glucose transport. There was no change in the plasma-to-lumen flux of sodium in the infected loop during simultaneous absorption of glucose.

\section{DISCUSSION}

The main symptom in cholera infection is the rapid loss of a large amount of fluid by the intestinal wall. Contrary to an earlier view, this occurs while the patient retains a morphologically intact intestinal mucous membrane. It therefore appears that the vibrio is causing a subtler change in the mucosal epithelium than its removal. A possible basis for 
understanding this change lies in the unidirectional fluxes of water and sodium ions across the intestinal mucosa (Visscher, Vargo, Carr, Dean, and Erickson, 1944; Fordtran, Levitan, Bikerman, Burrows, and Ingelfinger, 1961), their magnitude in man (Love, Mitchell, and Phillips, 1968) being sufficient to account for the large volumes of diarrhoeal stool found in the human disease.

The present studies using a loop of adult rabbit small intestine in vivo have shown that the loop becomes distended with fluid having the composition of cholera stool. This was due to an increase in the unidirectional flux of sodium ion from plasma to lumen and so to a net accumulation of sodium in the intestinal lumen. Huber and Phillips (1960), however, believe that the effect of the vibrio is to decrease the flux of sodium ion from lumen to plasma. This conclusion is based on the observation that vibrio inhibit the short circuit current of the frog skin. The short circuit current in the frog skin and small intestine (Schultz and Zalnsky, 1964) is a measure of net active sodium transport and not of unidirectional flux. It will be decreased, therefore, by either reduction in lumen-to-plasma flux or an increase in plasma-to-lumen flux (Fuhrman, 1952). The results of Huber and Phillips (1960) could therefore be equally well explained by an increased movement of sodium ions into the intestinal lumen rather then by decreased lumen-to-plasma movement. This would be in agreement with the evidence now presented from the small intestine.

This concept of increased movement of sodium ions through the mucosal cell is also in keeping with other work. Ling (1965) believes that the term 'sodium pump' does not imply anything more than a cellular barrier to massive fluid and electrolyte movement by normal mucosa. In cholera this barrier appears to be disrupted so that the cell cannot accumulate sodium against a concentration gradient. This leakiness of mucosal cells may not even be transcellular but involve changes in the 'shunt path' (Ussing and Windhager, 1964). Cholera stool and vibrio filtrates have been shown to affect the permeability of capillaries in the skin of guinea pigs and rabbits (Craig, 1965) so that the observed effect in the intestine may not be peculiar to intestinal epithelium.

The accumulation of fluid in intestinal loops has been demonstrated in infected bowel where a number of toxic vibrio products may be operating. In the studies exposing the mucosa to toxin without vibrio the results were similar but must be interpreted with caution, since in the preparation of the JenkinRowley toxin a concentration of $0.8 \mathrm{mMol}$ ammonium chloride is finally present in the final product. This concentration of ammonium chloride has been shown to inhibit fluid absorption in intestinal sacks and loops and also to reduce the short circuit current produced by active sodium transport by the frog skin (Neptune and Mitchell, 1965).

Further evidence of the integrity of the lumen-toplasma-sodium flux is seen in the absorption of glucose by the infected loops. Czaky (1964) believes that glucose and sodium share a common transport system. In the present studies glucose absorption was not depressed in the cholera loop, and if the common transport hypothesis is correct, then this would make the isolated inhibition of the sodium pump unlikely. These absorptive processes are thought to be dependent on ATPase (Newey, 1967). Studies by Richardson and Evans (1965) have shown that vibrio extracts have no effect on the ATPase activity in preparations of intestinal microvilli. It is possible that some of the glucose effect is due to solvent drag, but, according to Ussing (1963), this would decrease the plasma-to-lumen flux which has not been observed in the present studies. The finding that simultaneous glucose absorption enhances lumen-to-plasma flux of sodium, and consequently net sodium and water absorption in the presence of cholera vibrio is further evidence of the metabolic integrity of the mucosal cell.

The present studies therefore indicate that the accumulation of fluid in the cholera-infected intestine of the rabbit is due to excessive movement of sodium ions into the lumen and not to depression of ionic movement out of the lumen. This seems to represent increased cellular permeability rather than inhibition of the mucosal sodium pump. This conclusion is in agreement with the original suggestion of Becquerel (1849).

\section{SUMMARY}

The effects of cholera vibrio and their products have been studied in vivo in a rabbit intestinal loop preparation. The accumulation of luminal fluid similar to cholera stool in man was observed. The net sodium content was accounted for by an increase in plasma-to-lumen unidirectional ionic flux and not to a decreased lumen-to-plasma flux. Simultaneous glucose absorption enhanced the latter flux and could result in net sodium absorption. These findings are consistent with an increased mucosal cell permeability rather than sodium pump inhibition.

The author wishes to thank Dr R. A. Phillips for his support and many helpful suggestions throughout these studies, Mrs C. Jacobi for technical assistance, and the Medical Research Council (G.B.) for the travelling fellowship during the tenure of which this work was done. 


\section{REFERENCES}

Becquerel, A. (1849). Note relative à quelques analyses du sang, des vomissements, des évacuations alvines et des urines des cholériques. Arch. gen. Méd., ser. 4, 21, 192-206.

Craig, J. O. (1965). The effect of cholera stool and culture filtrates on the skin of guinea pigs and rabbits. In Proceedings of the Cholera Research Symposium, Honolulu, pp. 153-158. Edited by O. A. Bushnell and C. S. Brookhyser. N.I.H., Washington, D.C

Czáky, T. Z. (1964). Intestinal absorption: changing concepts and ideas. Gastroenterology, 47, 201-205.

De, S. N., and Chatterje, D. N. (1953). An experimental study of the mechanisms of action of Vibrio cholerae on the intestinal mucous membrane. J. Path. Bact., 66, 559-562.

Fordtran, J. S., Levitan, R., Bikerman, Y., Burrows, B. A., and Ingelfinger, F. J. (1961). The kinetics of water absorption in the human intestine. Trans. Ass. Amer. Phycns, 74, 195-206.

_- Rector, F. C., Jr, Ewton, M. F., Soter, N., and Kinney, J. (1965). Permeability characteristics of the human small intestine. J. clin. Invest., 44, 1935-1944.

Fuhrman, F. A. (1952). Inhibition of active sodium transport in the isolated frog skin. Amer.J. Physiol., 171, 266-278.

Huber, G. S., and Phillips, R. A. (1960). Cholera and the sodium pump. In Proc. SEATO Cholera Symp, pp. 37-40. Edited by O. A. Bushnell and C. S. Brookhyser. N.I.H., Washington, D.C.

Jenkin, C. R., and Rowley, D. (1959). Toxic proteins from Vibrio cholerae and water vibrios which are lethal for mice. J. gen. Microbiol., 21, 191-202.

Ling, G. N. (1965). Thoughts on the molecular mechanism of the normal intestinal mucosa as a barrier to sodium ion movement and massive fluid loss in cholera. In Proceedings of the Cholera
Research Symposium, Honolulu, pp. 103-106. Edited by O. A. Bushnell and C. S. Brookhyser. N.I.H., Washington, D.C.

Love, A. H. G., Mitchell, T. G., and Phillips, R. A. (1968). Water and sodium absorption in the human intestine. J. Physiol. (Lond.), 195, 133-140.

Neptune, E. M., Jr., and Mitchell, T. G. (1965). Ammonium toxicity, a potential artifact in preparation of toxins. In Proceedings of the Cholera Research Symposium, Honolulu, p. 159. Edited by O. A. Bushnell and C. S. Brookhyser. N.I.H., Washington, D.C.

Newey, H. (1967). Absorption of carbohydrates. Brit. med. Bull., 23, 236-240.

Richardson, S. H., and Evans, D. J., Jr (1965). The effects of Vibrio cholerae extracts on membrane transport mechanisms. In Proceedings of the Cholera Research Symposium, Honolulu, pp. 139-144. Edited by O. A. Bushnell and C. S. Brookhyser. N.I.H., Washington, D.C.

Schultz, S. G., and Zalusky, R. (1964). Ion transport in isolated rabbit ileum. I. Short-circuit current and $\mathrm{Na}$ fluxes. J. gen. Physiol., 47, 567-584.

Ussing, H. H. (1963). Passage of materials across biological membranes. In Proceedings of the 1st International Pharmacological Meeting 1961, vol. 4, pp. 15-21. Edited by B. Uvnäs. Pergamon Press, Oxford.

- , and Windhager, E. E. (1964). Nature of shunt path and active sodium transport path through frog skin epithelium. Acta physiol. scand., 61, 484-504.

Visscher, M. B., Yargo, R. H., Carr, C. W., Dean, R. B., and Erickson, D. (1944). Sodium ion movement between the intestinal lumen and the blood. Amer. J. Physiol., 141, 488-505.

Watten, R. H., Morgan, F. M., Songkhla, Y. N., Yanikiati, B., and Phillips, R. A. (1959). Water and electrolyte studies in cholera. J. clin. Invest., 38, 1879-1889. 